\title{
Factors Affecting Movie Selection of Audiences in Bangkok
}

\author{
Amornsri Tanpipat, Sirijanya Kuawiriyapan, and Taweerapat Eiamcharoon
}

\begin{abstract}
This study investigates the behavior and factors affecting movie selection of audiences in the Bangkok area. A total of 390 respondents was surveyed via questionnaire. The results showed that the respondents liked to see American action movies. They saw movies for entertainment purposes and attended the cinema 1-2 times a month on the weekends. The results for marketing mix factors affecting movie selection show that for product factors the respondents mostly emphasized content and type of film. For price, they focused on a reasonable price. For distribution channel, they prioritized the cinema, and in terms of marketing communication, they gave precedence to movie trailers.
\end{abstract}

Keywords-Consumer behavior, Decision making for consumption, Movie selection

\section{INTRODUCTION}

$\mathrm{I}^{\mathrm{N}}$ $\mathrm{N}$ Thailand, the film production business is experiencing a depression for various reasons, including lack of capital, location, plot, and consumer acceptance. Accordingly, Thai films are not as popular as they should be and they account for only $13 \%-15 \%$ of all movies in the cinema [1]. Most Thai movies are ghost stories or comedies, resulting in a lack of variety in Thai movies in comparison to foreign movies. Research into factors affecting the movie selection of audiences in Bangkok should reveal the factors that can be further applied in development of the movie production business.

\section{LITERATURE REVIEW}

The results of the study of consumer behavior with respect to movie seeing in Bangkok [2] revealed that the majority of respondents liked to see action movies with friends in the evening between 5:00 p.m. and 9:00 p.m. on the weekend. On average, they saw a movie once a month. The respondents preferred foreign films for entertainment. As for marketing mix factors, the respondents focused on theaters the most, followed by pricing and promotion.

Reference [3] studied audience behavior with respect to

Amornsri Tanpipat: Faculty of Administration and Management, King Mongkut's Institute of Technology Ladkrabang, Thailand, (corresponding author's phone: +6689662 9466; e-mail: ktamorns@ gmail.com).

Sirijanya Kuawiriyapan: Faculty of Administration and Management, King Mongkut's Institute of Technology Ladkrabang, Thailand, (e-mail: gunkmitl@hotmail.com).

Taweerapat Eiamcharoon: Faculty of Administration and Management, King Mongkut's Institute of Technology Ladkrabang, Thailand, (e-mail: taweekrit@hotmail.com). foreign movie selection. The results of that study indicated that most respondents liked to see American action movies with their friends or lovers. They saw movies 1-2 times per month for entertainment purposes.

Reference [4] studied the key factors affecting consumer decision-making behavior in the cinema context using a mixed-method approach. The results revealed nine factors affecting film consumers' decision making: film synopsis and reviews, director and actors, genre, film adaptation, story, neutral information, schedule, visual effects, and objectionable content.

\section{RESEARCH METHOD}

\section{Data Collection}

In this study, the data were collected from questionnaires distributed to people who see movies in cinemas in Bangkok.

\section{Sample Group}

The respondents were randomly selected from all districts in Bangkok. In this study, Bangkok was divided into six districts and 65 people were selected from each district; therefore, the study had 390 participants.

\section{Instruments for Data Collection}

The instrument used in collecting data was a questionnaire composed of three parts:

Part I - Demographic data of the participants

Part II - Participants' behavior in seeing movies in cinemas

Part III - Factors affecting the selection of movies, considering product, price, distribution channel, and marketing communication

\section{Data Analysis}

The frequency and percentages are used in analyzing respondents' personal data and behavior in seeing movies in cinemas. As for the marketing mix factors, a Likert scale is used. The points assigned are as follows:

5 means the factor receives "the most importance"

4 means the factor receives "much importance"

3 means the factor receives "moderate importance"

2 means the factor receives "little importance"

1 means the factor receives "the least importance"

For each question, this study uses the mean score of the answers. The values are defined as follows: $1.00-1.80$ average means the least importance, $1.81-2.60$ average means less importance, 2.61 - 3.40 average means medium importance, 3.41 - 4.20 average means high importance, and 4.21 - 5.00 average means the highest importance. 


\section{RESEARCH RESULTS}

\section{Demographic Data of the Participants}

The result of the study revealed that of 390 participants, $75.60 \%$ was female. Most of the participants were $18-25$ years old $(56.41 \%)$ and single $(83.08 \%)$. Also, $88.21 \%$ had completed a bachelor's degree while $9.23 \%$ had obtained higher degrees. Regarding occupation, $59.74 \%$ was employed in private companies whereas $25.38 \%$ was students. Most (50.77\%) had an income between THB 10,001 and 20,000, followed by those with an income of THB 20,001 to 30,000 (37.44\%) (Table I).

TABLE I

DEMOGRAPHIC PROFILES OF RESPONDENTS

\begin{tabular}{lc}
\multicolumn{2}{c}{ DEMOGRAPHIC PROFILES OF RESPONDENTS } \\
\hline \hline \multicolumn{1}{c}{ Items } & Percentage \\
\hline Gender & \\
Female & 75.60 \\
Male & 24.40 \\
Age (years) & \\
$<18$ & 1.28 \\
$18-25$ & 56.41 \\
$26-30$ & 36.37 \\
$31-35$ & 4.36 \\
$36-40$ & 0.77 \\
$41-45$ & 0.26 \\
$>45$ & 0.26 \\
Marital status & \\
Single & 83.08 \\
Marriage & 16.92 \\
Education & \\
High school & 2.56 \\
Bachelor degree & 88.21 \\
Master degree & 9.23 \\
Occupation & \\
Employees in private companies & 59.74 \\
Students & 25.38 \\
Government officers & 9.74 \\
Business owners & 5.13 \\
Income per month (Thai Baht) & \\
-10,000 & 2.56 \\
10,001-20,000 & 50.77 \\
20,001-30,000 & 37.44 \\
30,001-40,000 & 8.97 \\
ב40,000 & 0.26 \\
\hline \hline
\end{tabular}

\section{Respondents' Behavior in Seeing Movies in Cinemas}

\subsection{Participants Seeing Movies}

The results showed that most respondents went to see movies with friends (37.4\%), followed by going with a lover (23.7\%); only $16.1 \%$ went to see movies with their families (Table II).

TABLE II

Participants Of SEeING Movie

\begin{tabular}{lc}
\hline \hline \multicolumn{1}{c}{ Participants of seeing movie } & Percentage \\
\hline Friends & 37.4 \\
Lover & 23.7 \\
Alone & 22.8 \\
Family & 16.1 \\
Total & 100.0 \\
\hline
\end{tabular}

\subsection{Source of Movies}

The study found that American movies were the most popular $(44.7 \%$ ) while $24.1 \%$ and $20.4 \%$ of the respondents liked to see European and Thai movies, respectively (Table III). This result corresponded with research [3], which revealed that the respondents liked American movies.

TABLE III SOURCE OF MOVIES

\begin{tabular}{|c|c|}
\hline Source of Movies & Percentage \\
\hline United States of America & 44.7 \\
\hline Europe & 24.1 \\
\hline Thailand & 20.4 \\
\hline Asia & 9.2 \\
\hline All sources & 1.5 \\
\hline Total & 100.0 \\
\hline
\end{tabular}

\subsection{Type of Popular Movies}

The most popular movies for the respondents were action movies $(28.12 \%)$, followed by adventure and fantasy movies (20.55\% and $19.47 \%$, respectively). In contrast, comedy movies, which are mostly selected for production by Thai entrepreneurs, had just $14.36 \%$ (Table IV). This result corresponded with the research of [2]-[3], which showed that the most popular movies were action movies.

TABLE IV

TYPE OF POPULAR MOVIES

\begin{tabular}{lcc}
\hline \hline & Type of Movies & Percentage \\
\hline Action Movies & & 28.12 \\
Adventure Movies & 20.55 \\
Fantasy Movies & & 19.47 \\
Cartoon Movies & & 17.50 \\
Comedy Movies & & 14.36 \\
& Total & 100.00 \\
\hline \hline
\end{tabular}

\subsection{Frequency of Seeing Movies}

The respondents saw movies at cinemas 1-2 times per month (41.8\%). While most respondents saw movies less than 1 time per month (41.0\%), only a few saw movies more than 4 times per month (Table V).

TABLE V

FREQUENCY OF SEEING MOVIE

\begin{tabular}{|c|c|}
\hline Frequency of Seeing Movie & Percentage \\
\hline$<1$ Time/month & 41.0 \\
\hline 1-2 Times/month & 41.8 \\
\hline 3-4 Times/month & 10.3 \\
\hline$>4$ Times/month & 6.9 \\
\hline Total & 100.0 \\
\hline
\end{tabular}

\subsection{Purpose in Seeing Movies}

The results of the study indicated that $29.3 \%$ of the respondents saw movies for entertainment. In addition, they saw movies because of plot preference and relaxation in similar proportions of $20.1 \%$ and $20.0 \%$, respectively (Table VI). This result corresponded with the research of [2]-[3], which showed that audiences saw movies for entertainment purposes.

\section{Factors Affecting Movie Selection of Audiences}

The marketing mix was analyzed based on factors related to product, price, distribution channel, and marketing communication. The results of the study revealed that the respondents rated the importance of the marketing mix as a whole at the high level, with a mean score of 3.77 , whereas the price factor had a highest average (Table VII). 
TABLE VI

AIM TO SEE MOVIES

\begin{tabular}{lc}
\hline \hline \multicolumn{1}{c}{ Aim to See Movies } & Percent \\
\hline Entertainment & 29.3 \\
Movie Plot Preference & 20.1 \\
Relaxation & 20.0 \\
Actor Preference & 11.9 \\
Crazy to See the Movie & 10.9 \\
Go with Friends or Lover & 5.8 \\
Learn Technical of Movie Production & 2.0 \\
Others & 0.2 \\
& Total \\
\hline \hline
\end{tabular}

TABLE VII

MeAns Of THE IMPORTANCE Of THE MARKeting MiXed FaCtors

\begin{tabular}{lcc}
\hline \hline Marketing Mixed Factor & Average & $\begin{array}{c}\text { Important } \\
\text { Level }\end{array}$ \\
\hline Price & 4.04 & High \\
Product & 3.73 & High \\
Marketing Communication & 3.71 & High \\
Distribution Channel & 3.60 & High \\
$\quad$ Total & 3.77 & High \\
\hline \hline
\end{tabular}

\subsection{Product}

Most respondents rated the importance of the product itself at the high level, with a mean score of 3.73. Upon consideration of each item, they rated at the highest level two items: movie plot and type of movie. Moreover, the video and audio, the actors, the soundtrack, and dubbing were rated at the high level. It was interesting to note that respondents gave only moderate precedence to the director and the length of the movie (Table VIII).

\begin{tabular}{lcc}
\multicolumn{3}{c}{ TABLE VIII } \\
PRODUCT FACTOR \\
\hline \hline Product Factor & Average & Important Level \\
\hline Type of Movie & 4.24 & Highest \\
Video and Audio of Movie & 3.94 & High \\
Actors & 3.78 & High \\
Soundtrack of the Movie & 3.45 & High \\
Dubbing & 3.44 & High \\
Director & 3.22 & Moderate \\
Length of Movie & 3.22 & Moderate \\
$\quad$ Total & 3.73 & High \\
\hline \hline
\end{tabular}

\subsection{Price}

The results showed that the respondents rated the importance of every item of price at the high level (Table IX).

\begin{tabular}{lll}
\multicolumn{3}{c}{$\begin{array}{c}\text { TABLE IX } \\
\text { PRICE FACTOR }\end{array}$} \\
\hline \hline \multicolumn{1}{c}{ Price Factor } & Average & $\begin{array}{l}\text { Important } \\
\text { Level }\end{array}$ \\
\hline $\begin{array}{l}\text { Reasonable price for quality } \\
\text { of movie }\end{array}$ & 4.07 & High \\
$\begin{array}{l}\text { Reasonable price for } \\
\text { convenience of seeing movie } \\
\text { Total }\end{array}$ & 4.05 & High \\
\hline \hline
\end{tabular}

\subsection{Distribution Channel}

The respondents rated the importance of the distribution channel at the high level (mean $=3.60)$. The distribution channel via cinemas was rated at the highest level while the mobile phone app was rated at the high level. Distribution via CD or DVD was rated at the moderate level (Table X)
TABLE X

DISTRIBUTION CHANNEL

\begin{tabular}{lll}
\hline \hline Distribution Channel & Average & Important Level \\
\hline Cinemas & 4.27 & Highest \\
Application on mobile phone & 3.45 & High \\
Dealer of Movie CD and DVD & 3.08 & Moderate \\
Total & 3.60 & High \\
\hline \hline
\end{tabular}

3.4 Marketing Communication

The results of the study revealed that the factors regarding the marketing communication were rated at the high level, with a mean score of 3.71. For each item, the respondents rated movie trailers at the highest level. On the other hand, they rated three items at the high level, including social media, advertising on television and multimedia, and movie posters (Table XI). Reference [5] reported that the influence of Facebook on the respondents' decision to watch a movie was at the medium level. In addition, positive comments about the movie and promotion of the movie on Facebook were the most influential factors for the respondents. In addition, reference [6] suggested that kudos from reviewers formed a key success factor in the motion picture industry.

TABLE XI

MARKETING COMMUNICATION CHANNEL

\begin{tabular}{lcc}
\hline \hline Marketing Communication & Average & Important Level \\
\hline Movie Trailers & 4.46 & Highest \\
Social Media & 4.14 & High \\
Advertising on Television & 3.73 & High \\
and Multimedia & 3.64 & High \\
Movie Posters & 3.26 & Moderate \\
Movie-Related Souvenir & 3.08 & Moderate \\
Premiere press conference & 3.71 & High \\
$\quad$ Total
\end{tabular}

\section{REFERENCES}

[1] Kasikorn Research Center. " 49 years of film industry : development to rise to the level of exports", [Online]. Available : http://positioningmag.com/27821. 2006. unpublished

[2] W. Thongmak, "The Consumer Behavior Towards Movie Seeing in Bangkok", Independent study. Rajamangala University of Technology Thanyaburi. 2006. unpublished

[3] M. Sathaporn, "Behavior of seeing foreign movie of audiences in Bangkok", Independent study. Dhurakij Pundit University. 2015. Unpublished

[4] D. H. Suwarto, "Identifying Key Factors Affecting Consumer Decision Making Behavior in Cinema Context: A Mix Method Approach," in Conf. Rec. 2012 The 2012 International Conference on Contemporary Business and Management (ICOM2012)10-12 December 2012 Bangkok, Thailand, pp.392-416.

[5] W. Bunsorn, "Influence of facebook for movies selecting of teenagers in Bangkok", Independent study. Sripatum University. 2014. unpublished

[6] B. R. Litman and L. S. Kohl, "Predicting financial success of motion pictures: The '80s experience", J. Media Economics, vol. 2, Feb 2009, pp. 35-50.

Amornsri Tanpipat was born in Nakornsawan Province, Thailand. She received a B.Sc. in Agriculture from Kasetsart University, Thailand. She received a M.B.A. from National Institute of Development Administration, Thailand. She is an associate professor at faculty of Administration and Management, King Mongkut's Institute of Technology, Ladkrabang (KMITL), Thailand. She has published articals in International Journal of Arts and Sciences. Her current research in the broad area of marketing, Consumer Behavior.

Sirijanya Kuawiriyapan was born in Bangkok, Thailand. She received a B.Sc. in Agri-Education from Kasetsart University, Thailand. She received a M.Sc . in Agri-Extension from Kasetsart University, Thailand. She is an 
associate professor at faculty of Administration and Management, King Mongkut's Institute of Technology, Ladkrabang (KMITL), Thailand. She has published articals in International Journal of Arts and Sciences, Journal of the ooi Junior Academy, King Mongkut's Agriculture Journal. Her current research in the broad area of marketing, Consumer Behavior, Integrated Marketing Communication and Management.

Taweerapat Eiamcharoon was born in Chachoengsao, Thailand. $\mathrm{He}$ received the Bachelor of Business Administration (B.B.A) from Faculty Administration and Management and the Master of Business Administration (M.B.A) from King Mongkut's Institute of Technology, Ladkrabang (KMITL), Thailand. 